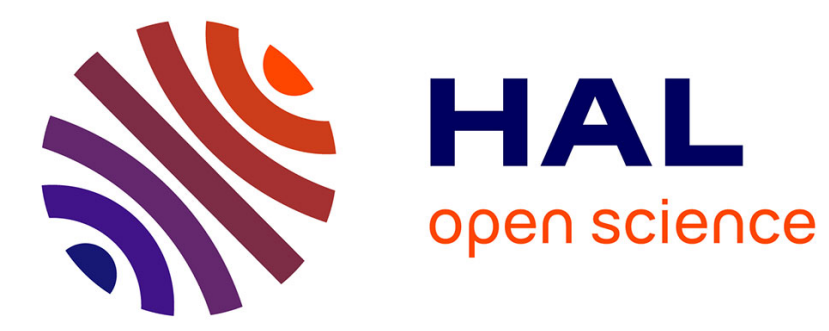

\title{
The Wiener Filter Applied to EMI Decomposition
}

Piotr Musznicki, Jean-Luc Schanen, Pierre Granjon, Piotr Chrzan

\section{To cite this version:}

Piotr Musznicki, Jean-Luc Schanen, Pierre Granjon, Piotr Chrzan. The Wiener Filter Applied to EMI Decomposition. IEEE Transactions on Power Electronics, 2008, 23 (6), pp.3088-3093. 10.1109/TPEL.2008.2004873 . hal-00349929

\section{HAL Id: hal-00349929 \\ https://hal.science/hal-00349929}

Submitted on 5 Jan 2009

HAL is a multi-disciplinary open access archive for the deposit and dissemination of scientific research documents, whether they are published or not. The documents may come from teaching and research institutions in France or abroad, or from public or private research centers.
L'archive ouverte pluridisciplinaire HAL, est destinée au dépôt et à la diffusion de documents scientifiques de niveau recherche, publiés ou non, émanant des établissements d'enseignement et de recherche français ou étrangers, des laboratoires publics ou privés. 


\title{
The Wiener Filter Applied to EMI Decomposition
}

\author{
Piotr Musznicki, Jean-Luc Schanen, Senior Member, IEEE, Pierre Granjon, and Piotr J. Chrzan, Member, IEEE
}

\begin{abstract}
This paper presents a DSP method that allows decomposing conducted electromagnetic interference (EMI) emissions from different sources in large power electronics systems. The estimation process is carried out by a number of Wiener filters (WFs), which represent all different converter states. These are determined by initial commutation event conditions and propagation paths layout. Filters are fed by a semiconductor power switch voltage or current waveforms regarded as sources of perturbation. The EMI emissions are measured on the line impedance stabilization network (LISN) terminals. Optimal filter adaptation is carried out in the frequency domain by measuring and computing input and cross-power signal spectra. Analysis of a parallel quasi-resonant dc-link voltage inverter (PQRDCLI) is outlined to distinguish filters assigned for inverter operation from those for external dc/dc converter interaction. Experimental results are given to illustrate the WF estimation quality. The possibility of detailed decomposition of the LISN-EMI waveforms is depicted in both time and frequency domains. Comparative analysis of frequency responses for PQRDCLI-link voltage changes is given.
\end{abstract}

Index Terms-DC-DC power conversion, electromagnetic interference (EMI), resonant power conversion, Wiener filtering (WF).

\section{INTRODUCTION}

$\mathbf{N}$ OWADAYS, switching frequencies of power semiconductor devices are being increased in order to reduce geometrical dimensions and weight of power converters. This, however, leads to increased electromagnetic interference (EMI) emissions. Power electronics systems often contain more than one converter (see Fig. 1). Each one is composed of more than a single power semiconductor switch. All these different fast switching devices generate undesired electromagnetic noise that contributes to the general electromagnetic compatibility (EMC) emission signal. The magnitude of emitted noise relies on the electrical propagation conditions that depend on geometrical structures of the system, device packaging, layout of the circuit,

Manuscript received April 2, 2008; revised June 10, 2008. First published November 17, 2008; current version published December 9, 2008. Recommended for publication by Associate Editor P. Tenti.

P. Musznicki and P. J. Chrzan are with the Department of Power Electronics and Electrical Machines, Faculty of Electrical and Control Engineering, Gdansk University of Technology, Gdansk PL-80-216, Poland (e-mail: p.musznicki@ely.pg.gda.pl; p.chrzan@ely.pg.gda.pl).

J.-L. Schanen is with Grenoble Electrical Engineering Laboratory (G2ELab), Mixed Unit of Research (UMR) 5529, Grenoble Institute of Technology (INPG)/Joseph Fourier University (UJF), National Center for Scientific Research (CNRS), Ecole Nationale Supérieure of Electrical Engineers of Grenoble (ENSIEG), BP 46-38402 Saint-Martin-d'Heres Cedex, France (e-mail: jean-luc.schanen@g2elab.inpg.fr).

P. Granjon is with Grenoble Image Speech Signal Automatics Laboratory (Gipsa-Lab), Mixed Unit of Research (UMR) 5216, Grenoble Institute of Technology (INPG)/Joseph Fourier University (UJF), National Center for Scientific Research (CNRS), Ecole Nationale Supérieure of Electrical Engineers of Grenoble (ENSIEG), BP 46-38402 Saint-Martin-d'Heres Cedex, France (e-mail: pierre.granjon@inpg.fr).

Color versions of one or more of the figures in this paper are available online at http://ieeexplore.ieee.org.

Digital Object Identifier 10.1109/TPEL.2008.2004873

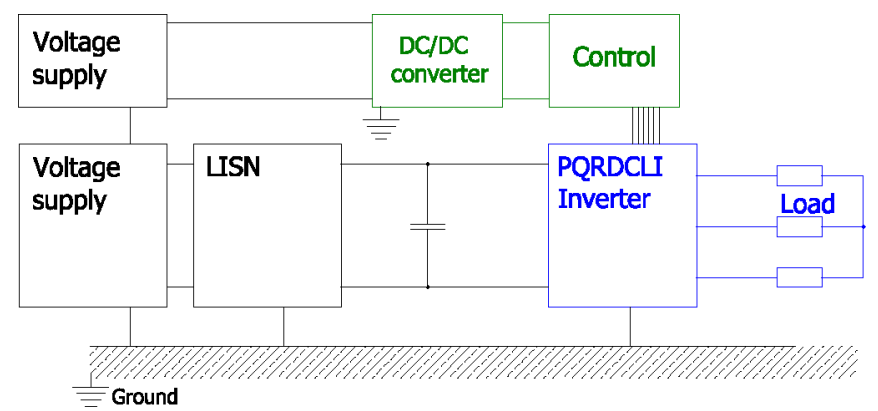

Fig. 1. Block diagram of a power electronics converter with two sources of perturbation.

parasitic components, and current $(\mathrm{d} i / \mathrm{d} t)$ and voltage $(\mathrm{d} v / \mathrm{d} t)$ slew rates [11]. Many official regulations have been issued for limiting the EMI [1], [2].

A problem may appear when a complex power electronics system, including more than one perturbation source, generates a noise that exceeds the allowable level. In a typical converter, it is impossible to turn off one or more subsystems (auxiliary circuit or control) in order to identify which part of perturbation comes from which subsystem. An example of such a converter with two identified sources of perturbations is depicted in Fig. 1. It consists of a parallel quasi-resonant dc-link voltage inverter (PQRDCLI) with the gate circuit power supply from an external $\mathrm{dc} / \mathrm{dc}$ converter. The primary source of perturbation has its origin in resonant discharge and recharge of the input capacitor, which precedes each inverter state's commutation. The operation of the switching $\mathrm{dc} / \mathrm{dc}$ supply generates another source of conducted propagated emissions in the circuits of the PQRDCLI. Therefore, for EMI mitigation in power electronics converters, new approaches are needed, which will allow separation of perturbations from different sources, and can also be helpful in the analyses and understanding of electromagnetic disturbance excitation. The circuit simulators like Saber, Spice [18], or TCad [15] allow investigation of the phenomena connected with perturbation generation and propagation in the early stages of converter development [7], but they require an accurate model of all system components. Therefore, in this paper, the perturbation reconstruction based on a DSP method - the Wiener filtering (WF) concept-is applied. The source identification method is used for determining the transfer function between the source and generated perturbations [13]. The proposed WF method applied to conducted EMI analysis allows one to numerically separate noise from more than one sources, and investigate an impact of each source and also the level and the propagation path of the perturbation.

This paper is organized as follows. An example of EMI separation for the PQRDCLI and the dc/dc converter for a control circuit supply is presented for the WF method application in 


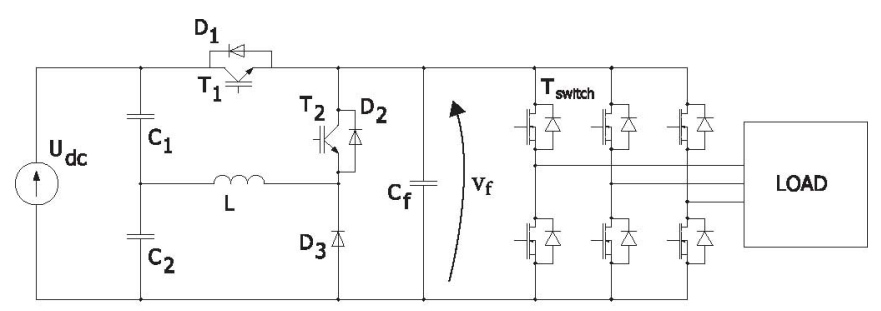

(a)

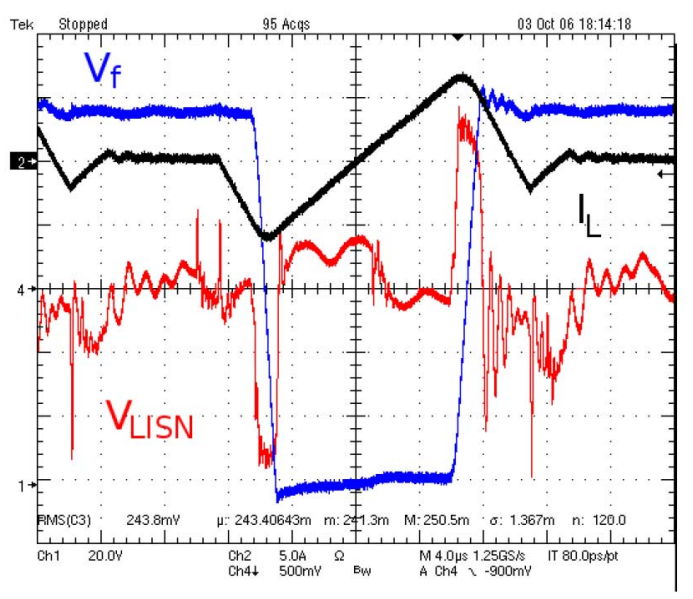

(b)

Fig. 2. Soft switching inverter. (a) PQRDCLI circuit topology. (b) Experimental waveforms.

Section II. In Section III, general WF methodology for EMI separation in a power electronics converter is described. Particular experimental EMI separation results using the WF method are illustrated in Section IV. Final conclusion of WF performance is given in Section V.

\section{SOFT-SWITCHING INVERTER}

Soft-switching techniques have been proposed to reduce switching losses and EMI, and to increase converter efficiency [5], [17]. The PQRDCLI circuit topology, as depicted in Fig. 2, is described in detail with the gating control procedure in [8] and [9]. The parallel quasi-resonant circuit is located in the dc link of an indirect frequency converter. It consists of two input electrolytic capacitors $C_{1}$ and $C_{2}$ connected in series. The inverter is separated from the dc voltage source by a bilateral switch based on transistor $T_{1}$ with diode $D_{1}$. When the bus line voltage $V_{f}$ decreases resonantly to zero, it allows soft zero voltage switching (ZVS) of inverter transistors and transistor $T_{1}$.

Each commutation in the inverter is preceded by reloading the resonant circuit in order to discharge the input capacitor $C_{f}$ to obtain a ZVS condition for commutation of the inverter bridge transistors. Sufficient energy required for the resonant operation must be stored in inductor L, used in conjunction with transistor $T_{2}$. The main source of EMI of the PQRDCLI is variation of the dc-link voltage $V_{f}$ across input inverter capacitor $C_{f}$. The perturbation generated is mainly due to the common mode current in this particular case. However, it can be noticed that the rise and fall times of this voltage are much lower than

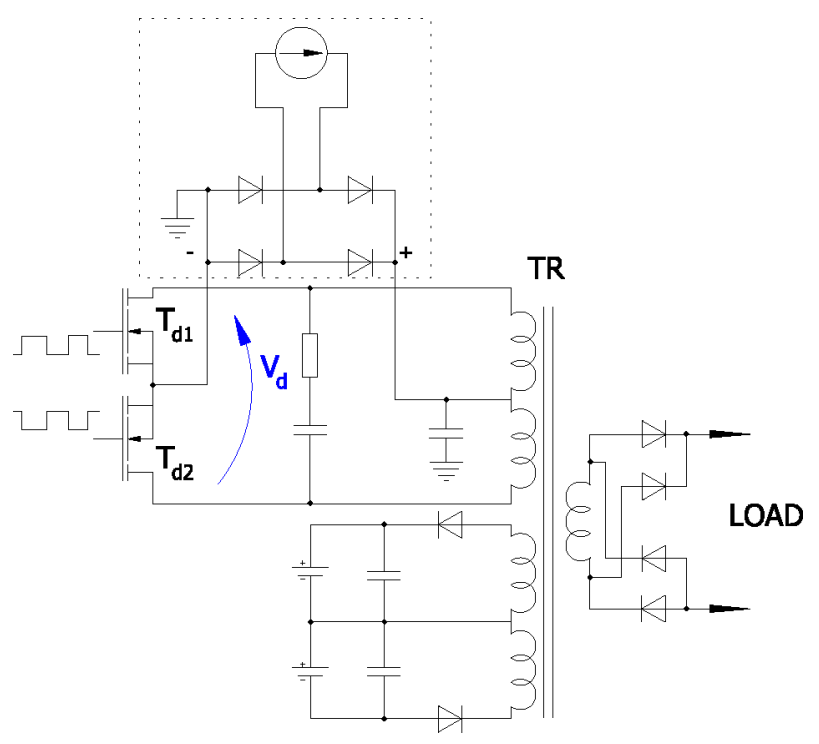

Fig. 3. DC/DC boost converter topology.

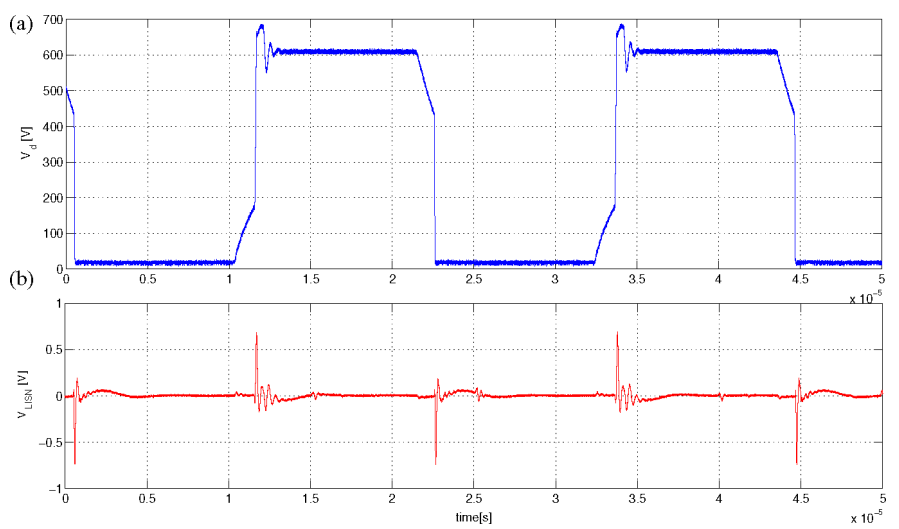

Fig. 4. Measured waveform generated only by dc/dc converter. (a) Voltage $V_{d}$. (b) Perturbation measured on LISN.

in a hard switching inverter. The differential mode (DM) is an infinitesimal quantity, because of the inductive nature of DM current paths for high frequency [6].

The control circuit and inverter insulated gate bipolar transistors (IGBTs) drivers are fed by a push-pull switch-mode dc power supply. Even if this additional converter is a low-power one, it generates noise, due to hard-switching commutation of $T_{d 1}$ and $T_{d 2}$ (see Fig. 3). The disturbance of this supply unit alone can be measured by turning off the power source, for verification purposes. The voltage across the $\mathrm{dc} / \mathrm{dc}$ switch-mode converter transistors and the perturbation measured on a line impedance stabilization network (LISN) are presented in Fig. 4. Switching frequency is $40 \mathrm{kHz}$. As is typical for push-pull topology, transistors must block the supply voltage twice.

Experimental setup presented in Fig. 5 contains the PQRDCLI fed from the dc power supply through the LISN (Schaffner NNB41). The inverter with a resonant circuit, the control unit including DSP and IGBT drivers, and the dc/dc converter have been placed on a common grounded radiator. 


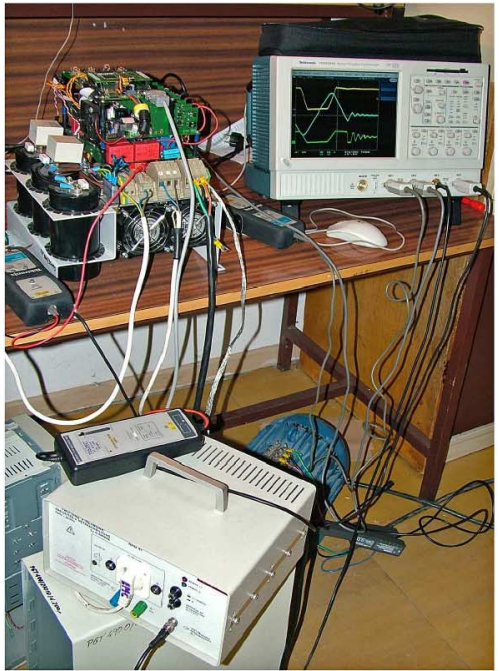

(a)

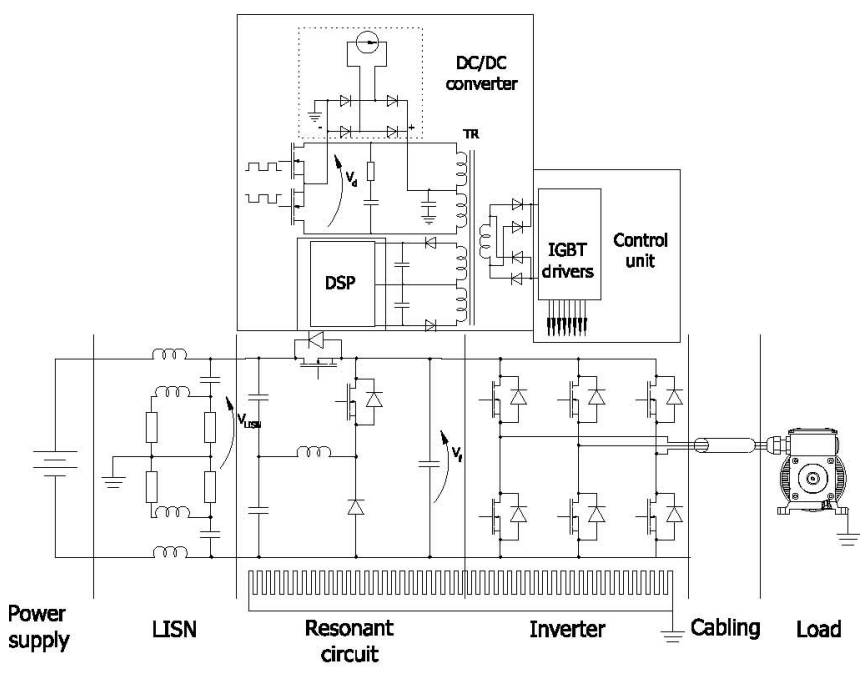

(b)

Fig. 5. Laboratory test bench. (a) View. (b) Circuit scheme.

Voltage waveforms and perturbations have been registered for different operating conditions using the oscilloscope TDS5034B of Tektronix with voltage differential probes. The sampling frequency was $250 \mathrm{MHz}$. The symmetrical inverter load was the induction machine $(3 \mathrm{~kW})$.

The perturbations measured on a $50-\Omega$ LISN resistor are generated by the whole system during a typical operation (see Fig. 6). Two power signals measured on the two converters have been chosen to separate the noise generated from each system: $V_{f}$, the dc-link voltage across input inverter capacitor $C_{f}$, and $V_{d}$, the voltage across the dc/dc converter transistors. It can be noted that EMI from the soft-switching inverter has the greatest peak amplitude, and so is the main source of EMI generation in this particular case. Moreover, there is an additional noise because of zero-current turn-on switching of transistor $T_{2}$. Although voltage $V_{d}$ across dc-switch-mode supply [see Fig. 6(b)] changes from 0 to $600 \mathrm{~V}$ (higher voltage than power inverter), the perturbations generated are smaller because of the topology of the circuit layout [12].
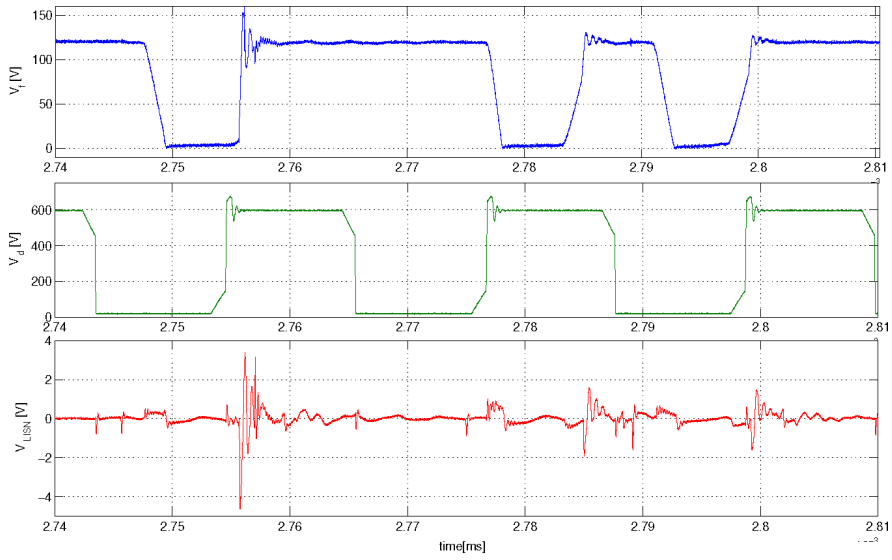

Fig. 6. Total EMI waveforms with two main sources of perturbation.

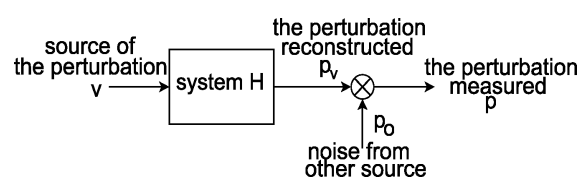

Fig. 7. WF in estimation of EMI.

\section{WIENER FILTERING}

The WF method in EMI analysis allows the linking of a source of perturbation with the perturbation generated. Power electronics signals can be obtained by measurements from working application or simulation results. Thus, this method can also be useful for EMI forecasting. The three stages of the WF method in EMI can be described as follows:

1) adaptation process, where the time or frequency response of the WF is calculated using data from measurement or simulation;

2) reconstruction of perturbation, generated independently by each EMI source;

3) perturbation superposition, contributing to the total noise generated by the converter registered across the LISN.

The theory of optimum linear filters for the general case of a minimum mean square error criterion was developed by Wiener for continuous-time systems and independently by Kolmogorov for discrete-time systems [10], [16]. In this approach, WFs used for the EMI estimation are fed by power switch voltage or current transients, as represented by the source of disturbances $v$ in Fig. 7.

The corresponding conducted network emissions $p$, which can be isolated in the LISN terminals, consist of so-called reconstructed disturbances $p_{v}$, which are available to be estimated with the aid of filtering source $v$ and inevitably present additive noise term $p_{o}$.

As the assumptions of WF theory claim: 1) that filter system $H$ is linear and time-invariant; 2) that noise $p_{o}$ coming from other sources is additive and not correlated with the source of disturbances $v$. One can express $v$ and $p_{v}$ in the frequency domain by the Fourier transform

$$
P_{v}(j \omega)=H(j \omega) V(j \omega)
$$

where $H(j \omega)$ is the filter frequency response. 
The estimation error $E_{r}(j \omega)$ is defined as the difference between the measured and reconstructed disturbances

$$
E_{r}(j \omega)=P(j \omega)-H(j \omega) V(j \omega) .
$$

Then, the mean square estimation error is given as follows:

$$
\widehat{E}\left\{\left|E_{r}(j \omega)\right|^{2}\right\}=\widehat{E}\left\{E_{r}^{*}(j \omega) E_{r}(j \omega)\right\}
$$

where $\widehat{E}\{\cdot\}$ denotes the mathematical expectation operator. By using (2) in (4), we obtain the value of $H(j \omega)$ that minimizes the mean square error criterion (3), i.e., the WF frequency response

$$
\frac{\partial}{\partial H(j \omega)} \widehat{E}\left\{\left|E_{r}(j \omega)\right|^{2}\right\}=0 .
$$

Hence, the value of $H(j \omega)$ is the frequency response of the optimal WF

$$
H(j \omega)=\frac{S_{v p}(j \omega)}{S_{v v}(j \omega)}
$$

where $S_{v v}(j \omega)=\widehat{E}\left\{[V(j \omega)]^{2}\right\}$ is the power spectrum of $v$, and $S_{v p}(j \omega)=\widehat{E}\left\{\left[P(j \omega) V^{*}(j \omega)\right]\right\}$ is the cross-power spectrum between $v$ and $p$. In order to estimate $H(j \omega)$, one must measure the data of input $v$ and output $p$ signals first. These data can then be used to estimate power and cross-power spectra of (5), and finally the frequency response of the optimal WF. Once this filter has been estimated, it can be applied to any form of source disturbance $v$ in order to predict the corresponding disturbances $p_{v}$. The same study can also be carried out in the time domain [16], where filter input-output relation is given by

$$
p_{v}(m)=\sum_{k=0}^{P-1} h_{k} v(m-k)=\mathbf{h}^{T} \mathbf{v}
$$

where $m$ is the discrete-time index, $\mathbf{v}^{T}=[v(m), v(m-$ $1), \ldots, v(m-P-1)]$ is the filter input signal, and the parameter vector $\mathbf{h}^{T}=\left[h_{0}, h_{1}, \ldots, h_{P-1}\right]$ is the WF coefficient vector. The error signal $e(m)$ is defined as in (2) as the difference between the desired signal $p(m)$ and the filter output signal $p_{v}(m)$

$$
e(m)=p(m)-p_{v}(m)=p(m)-\mathbf{h}^{T} \mathbf{v} .
$$

Here again, the optimal WF coefficients $\mathbf{h}$ have to minimize the mean square error defined through the expectation operator $\widehat{E}\{\cdot\}$ as

$$
\begin{aligned}
\widehat{E}\left[e^{2}(m)\right] & \left.=\widehat{E}\left[p(m)-\mathbf{h}^{T} \mathbf{v}\right)^{2}\right] \\
& =\widehat{E}\left[p(m)^{2}\right]-2 \mathbf{h}^{T} \widehat{E}[\mathbf{v} p(m)]+\mathbf{h}^{T} \widehat{E}\left[\left(\mathbf{v} \mathbf{v}^{T}\right)\right] \mathbf{h} \\
& =\mathbf{r}_{p p}(0)-2 \mathbf{h}^{T} \mathbf{r}_{v p}+\mathbf{h}^{T} \mathbf{R}_{v v} \mathbf{h}
\end{aligned}
$$

where $\mathbf{R}_{v v}=\widehat{E}\left[\mathbf{v v}^{T}\right]$ is the autocorrelation matrix of the input signal and $\mathbf{r}_{v p}=\widehat{E}[\mathbf{v} p(m)]$ is the cross-correlation vector of the input and the desired signal. The minimum mean square error WF is obtained by setting the gradient of the mean square error function with respect to the filter coefficient vector to zero

$$
\frac{\partial}{\partial \mathbf{h}} \widehat{E}\left[e^{2}(m)\right]=-2 \mathbf{r}_{v p}+2 \mathbf{R}_{v v} \mathbf{h}=0
$$

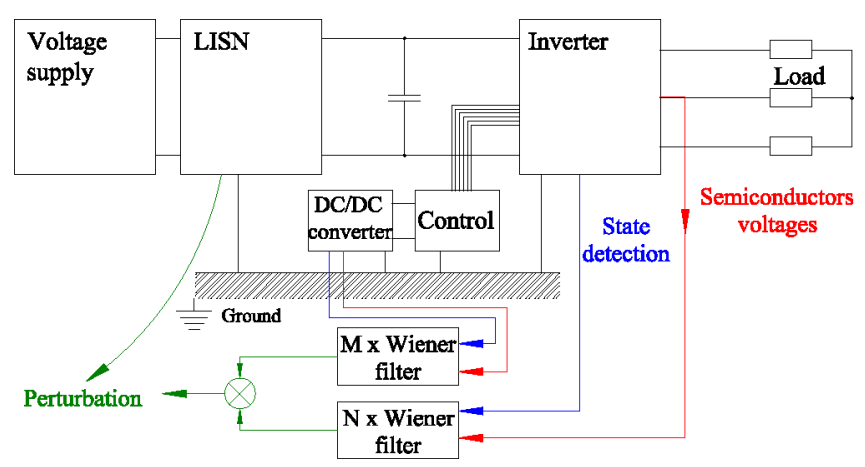

Fig. 8. WFs applied to EMI decomposition in the voltage inverter.

which gives the WF solution

$$
\mathbf{h}=\mathbf{R}_{v v}^{-1} \mathbf{r}_{v p} .
$$

Equations (5) and (9) are exactly the same relations, but expressed in the frequency and time domains, respectively. Moreover, experimental data (measured signals $v$ and $p$ ) can be used to estimate the WF characteristics in these two domains. Indeed, spectra $S_{v v}$ and $S_{v p}$ have to be calculated in the frequencydomain approach, and correlations $R_{v v}$ and $r_{v p}$ must be estimated in the time-domain approach. Well-known estimators have been proposed in the literature [14]. In the following, the time-domain approach will be used.

\section{WF METHOD APPLIED To EMI DECOMPOSITION}

In order to separate the perturbation, the transfer functions between each source and the perturbation should be calculated in the adaptation process following WF methodology. The voltages have been considered as the perturbation sources, because their measurement is easier than that of currents. $V_{f}$, the dc-link voltage, is used as an input signal for $N \mathrm{WFs}$, and $V_{d}$, the voltage from the $\mathrm{dc} / \mathrm{dc}$ converter, is used for $M \mathrm{WFs}$. The perturbation measured on the LISN should be taken as an output (see Fig. 8).

The use of several transfer functions $(N$ and $M$ ) is linked to the fact that each converter may propose various propagation paths, depending on its switch states. In this case, two different transfer functions $(N=2)$ are retained for the PQRDCLI in$\operatorname{verter}\left(T_{1}\right.$ ON or $\left.T_{2} \mathrm{OFF}\right)$, and also the two states for the push-pull auxiliary converter $(M=2)$, which also indicate two different configurations, are based on its switch states. The level and propagation path of the perturbation depend on the $d v / d t$ and circuit properties [3]. The participation of each component and the value of parameters in the EMI propagation change during a typical converter operation [4], [19]. Consequently, the transfer function is variable. Thus, the WFs, which are a numerical representation of all components, should be calculated for each subsequent state of the converter. Generally, $N$ transfer functions of WFs for the inverter and $M$ transfer functions for the additional $\mathrm{dc} / \mathrm{dc}$ converter should be calculated, where $N$ and $M$ are determined by the number of each circuit states. The detection of all converter states is needed, both in adaptation and estimation stages. This detection can be achieved either by 

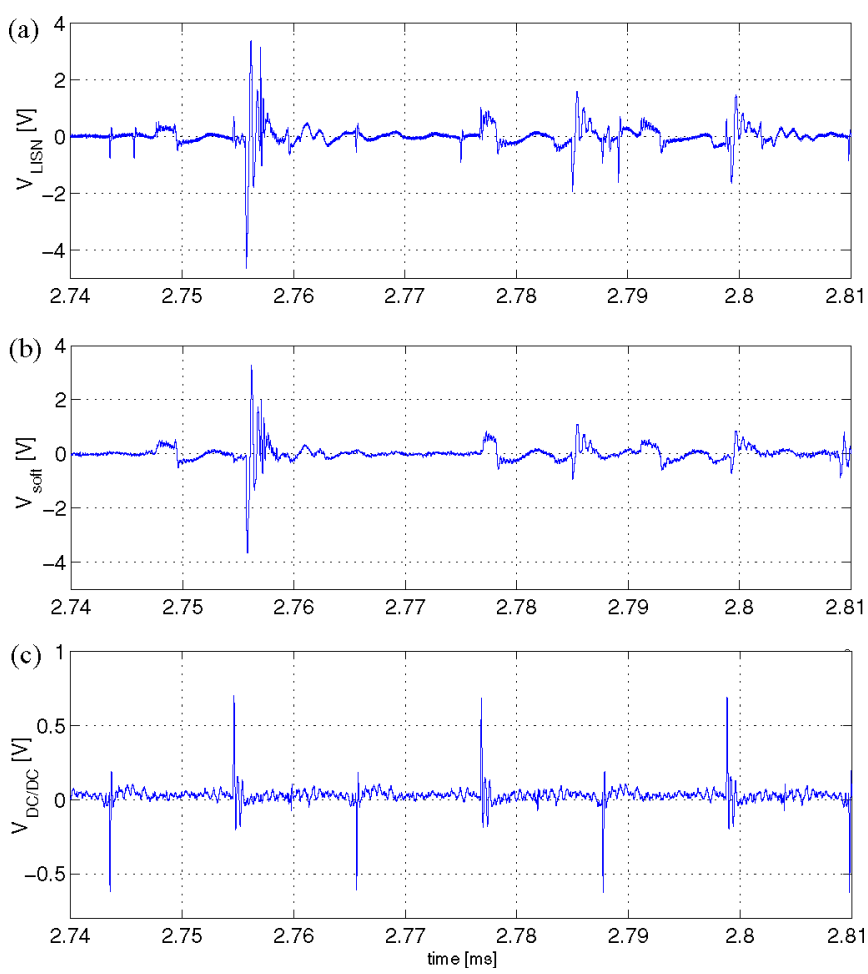

Fig. 9. Estimation and decomposition of experimental EMI waveforms. (a) Total LISN-EMI. (b) PQRDCLI inverter. (c) DC/DC external converter estimated contribution.

user knowledge or by using the measurement signals like IGBT gate circuit drivers.

By using the appropriate number of filters, one can separate EMI noise influence from more than one source, as is presented in Fig. 9, where the participation of perturbation from two independent sources is shown. It can be noted that the level of total perturbation [see Fig. 9(a)] contains the perturbation generated by the soft-switching inverter [see Fig. 9(b)] as well as the dc/dc converter [see Fig. 9(c)].

By comparing the perturbation generated during only the dc/dc converter operation [see Fig. 9(b)] and waveforms subtracted, with the WF, from total perturbation [see Fig. 9(c)], it can be noted that they are the same. It has been proved that separation from the WF method works correctly.

In Fig. 10, the total LISN noise is decomposed among the separate sources in the frequency domain. The WF method allows investigation of the importance and influence of the chosen source of perturbation on total noise. The level and the frequency range can be quantified for each source. Moreover, if the reconstructed signals do not agree with the real one, it suggests that another noise source exists in the converter.

In order to describe the EMI behavior of the PQRDCLI inverter, $N=2$ filters are used. Each filter, which is a numerical representation of the propagation path, can be applied to the perturbation reconstruction for one state of the inverter, in which it operates during some period. Thus, the filter frequency responses $H(j \omega)$ are different. The changing dc-link voltage across $C_{f}$ is the main source of perturbation for this case. The perturbation spectra generated by the PQRDCLI inverter can be
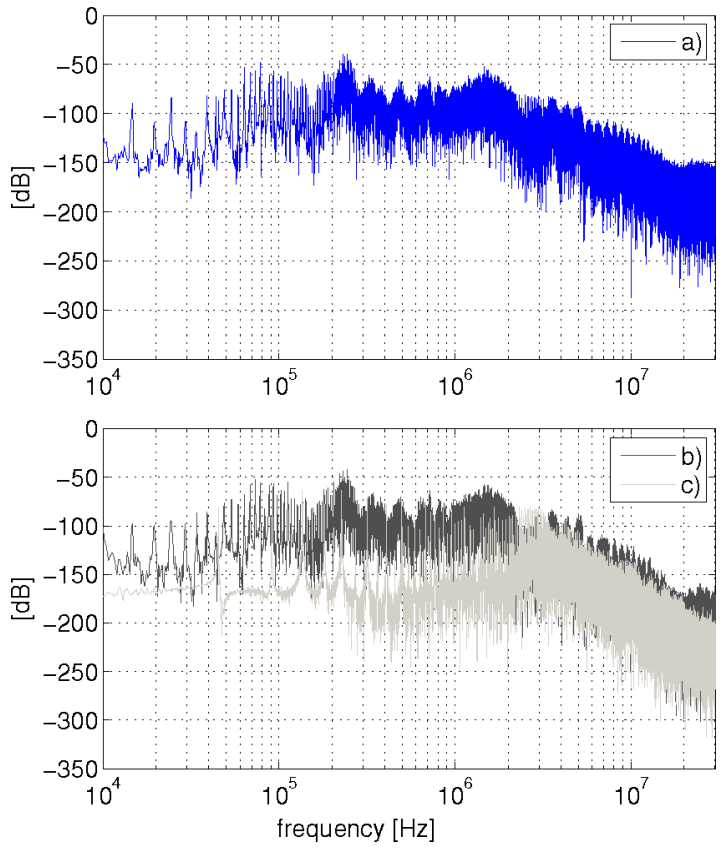

Fig. 10. Estimation and decomposition of experimental EMI spectra. (a) Measured total LISN-EMI spectrum. (b) PQRDCL inverter part. (c) DC/DC external converter estimated contribution.

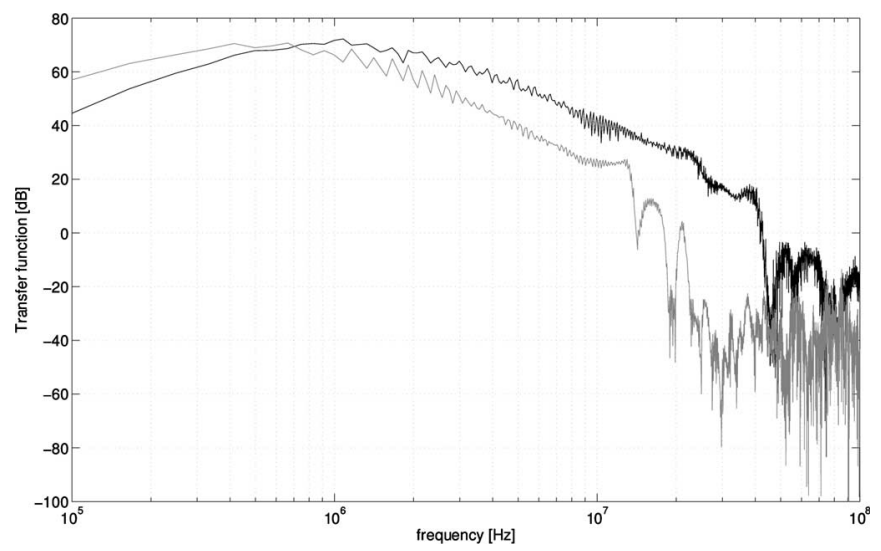

Fig. 11. Comparison of WFs frequency response for rising (marked gray) and falling (black) input inverter voltage.

equally decomposed into two separate frequency transmittances for each inverter state. Fig. 11 presents the comparison of the filter transfer functions, when voltage across $C_{f}$ rises up or falls down. The participation of all components in the propagation process and values of their parameters are different for these two states, which is the reason of the differences in the transfer function. Knowledge about the transfer function can be useful in reducing EMI; it allows one to find the information as to which part of a printed circuit board (PCB) layout should be changed or how to modify the turn-on or turn-off time for semiconductor devices.

\section{CONCLUSION}

WF applied to estimation of the conducted EMI emissions in soft-switching inverters was confirmed to be an efficient 
identification technique, as has been tested previously, for the case of a hard-switching inverter and a dc/dc boost converter. Identification of commutation disturbances allows the linking of voltages across switches with perturbations. It is possible to derive a transfer function or an impulse response in time domain for determining a relationship between the cause and effect of disturbances. The proper selection of different EMI propagation conditions defining a minimal number of converter states with its propagation path layout reflects a necessary number of WFs. Such an estimation structure gives powerful insight into EMI distribution. Moreover, it enables the decomposition of the EMI transients, indicating the contribution of its origin sources.

In the particularly examined application of the method to the PQRDCLI, two filters for dc-link voltage fall and rise changes and two filters for dc/dc converter operation have proved to be efficient for EMI estimation. Furthermore, identification of disturbances allows linking with high-accuracy commutation voltages across switches with the conducted EMI perturbations.

\section{REFERENCES}

[1] Electromagnetic Compatibility (EMC) Limits for Harmonic Current Emissions. European Committee for Electrotechnical Standardization (CENELEC) EN61000-3-2:2006, 2006.

[2] Electromagnetic Compatibility (EMC) Generic Standards. Emission standard for industrial environments European Committee for Electrotechnical Standardization (CENELEC) EN61000-6-4:2007, 2007.

[3] J. Guichon, J. L. Schanen, J. Roudet, B. Meille, and R. Revol, "Design of a PWM inverter regarding conducted EMC and losses: Influence of some key parameters," in Ind. Appl. Conf. 2005, 40th IAS Annu. Meeting. Conf. Rec. 2005, vol. 3, pp. 1855-1859.

[4] J. He, J. Jiang, J. Huang, and W. Chen, "Model of EMI coupling paths for an off-line power converter," in Proc. 19th Annu. IEEE Appl. Power Electron. Conf. Expo. 2004 (APEC 2004), vol. 2, pp. 708-713.

[5] W. Huang and G. Moschopoulos, "A new family of zero-voltage-transition PWM converters with dual active auxiliary circuits," IEEE Trans. Power Electron., vol. 21, no. 2, pp. 370-379, Mar. 2006.

[6] A. Kempski, "EMI noise splitting into common and differential modes in PWM inverter drive system," in Proc. IEEE Compat. Power Electron. 2005, Jun. 1, pp. 200-203.

[7] J.-S. Lai, H. Xudong, E. Pepa, C. Shaotang, and T. Nehl, "Inverter EMI modeling and simulation methodologies," IEEE Trans. Ind. Electron., vol. 53, no. 3, pp. 736-744, Jun. 2006.

[8] S. Mandrek and P. J. Chrzan, "Quasi-resonant dc-link inverter with a reduced number of active elements," IEEE Trans. Ind. Electron., vol. 54, no. 4, pp. 2088-2094, Aug. 2007.

[9] S. Mandrek and P. J. Chrzan, "Critical evaluation of resonant dc voltage link inverters for electrical drives," Electr. Power Quality Utilization J., vol. 10, no. 1/2, pp. 5-12, Dec. 2004.

[10] D. G. Manolakis, V. K. Ingle, and S. M. Kogan, Statistical and Adaptive Signal Processing: Spectral Estimation, Signal Modeling, Adaptive Filtering, and Array Processing. Norwood, MA: Artech House, 2005.

[11] J. Meng, W. Ma, Q. Pan, Z. Zhao, and L. Zhang, "Noise source lumped circuit modeling and identification for power converters," IEEE Trans. Ind. Electron., vol. 53, no. 6, pp. 1853-1861, Dec. 2006.

[12] P. Musznicki, J. Schanen, P. Granjon, and P. J. Chrzan, "Better understanding EMI generation of power converters," in Proc. IEEE 36th Power Electron. Spec. Conf. (PESC 2005), pp. 1052-1056.

[13] P. Musznicki, J.-L. Schanen, P. Granjon, and P. J. Chrzan, "EMI estimation for dc/ac hard switching converter using Wiener filter," in Proc. 12th Int. Power Electron. Motion Control Conf. EPE-PEMC 2006, pp. 473-478.

[14] P. Stoica and R. L. Moses, Spectral Analysis of Signals. Upper Saddle River, NJ: Prentice-Hall, 2005.

[15] R. Szczesny, K. Iwan, and M. Ronkowski, "TCAD simulation package for power electronic systems," in Proc. 5th Eur. Conf. Power Electron. Appl. 1993, Sep. 13-16, vol. 7, pp. 1-6.

[16] S.-V. Vaseghi, Advance Digital Signal Processing and Noise Reduction. New York: Wiley, 2000.
[17] C.-M. Wang, "A novel soft-switching single-phase ac-dc-ac converter using new ZVS-PWM strategy," IEEE Trans. Power Electron., vol. 22, no. 5, pp. 1941-1948, Sep. 2007.

[18] Y. Weens, N. Idir, J.-J. Franchaud, and R. Bausiere, "High-frequency modeling of an adjustable speed drive," in Proc. 12th Int. Power Electron. Motion Control Conf. EPE-PEMC 2006, pp. 456-461.

[19] R. Zhang, X. Wu, and T. Wang, "Analysis of common mode EMI for three-phase voltage source converters," in Proc. 34th Annu. IEEE Power Electron. Spec. Conf. 2003 (PESC'03), Jun., vol. 4, pp. 1510-1515.

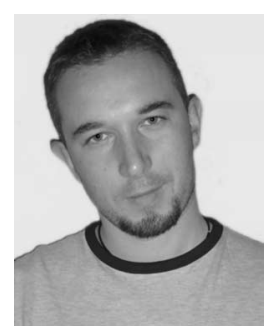

Piotr Musznicki was born in Slupsk, Poland, in 1976. $\mathrm{He}$ received the M.Sc. and Ph.D. degrees in power electronics from the Faculty of Electrical and Control Engineering, Gdansk University of Technology, Gdansk, Poland, in 2001 and 2006, and the Ph.D. degree from the Laboratoire d'Electrotechnique de Grenoble, Grenoble Institute of Technology (INPG), Grenoble, France, in 2006.

$\mathrm{He}$ is currently with Gdansk University of Technology, where he is engaged in power electronics and electrical machines. His current research interests include electromagnetic compatibility, modeling and control of power electronics converters and electrical machines, and DSP.

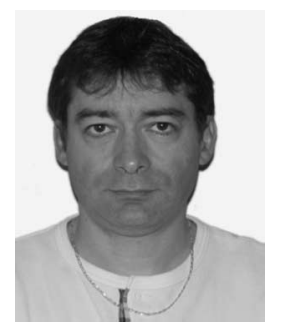

Jean-Luc Schanen (M'99-SM'04) was born in 1968. He received the Electr. Eng. Diploma and the Ph.D. degree in electromagnetic compatibility in power electronics from Grenoble Institute of Technology, Grenoble, France, in 1990 and 1994, respectively.

He is currently a Professor at Grenoble Institute of Technology (Grenoble INP), where since 1994, he has been with Grenoble Electrical Engineering Laboratory (G2ELab), and is engaged in the field of power electronics. His current research interests include technological design of power converters, and the use (or development, if not available) of any kind of modeling tools in order to improve the performances of power electronics converters, including electromagnetic compatibility and thermal aspects.

Prof. Schanen was the Chairman of the Power Electronics Devices and Components Committee, Industry Applications Society (IAS) between 2006 and 2007.

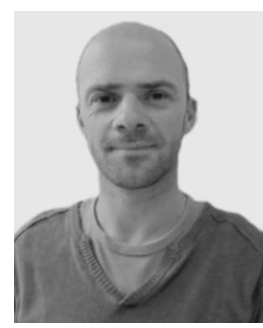

Pierre Granjon received the Ph.D. degree from Grenoble Institute of Technology (INPG), Grenoble, France, in 2000.

In 2002, he joined the Laboratory of Images and Signals (LIS), Grenoble Institute of Technology (INPG). In 2007, he joined Grenoble Image Speech Signal Automatics Laboratory (Gipsa-Lab), where he is currently an Associate Professor. His current research interests include signal processing applications in diagnosis and electrical engineering, such as fault diagnosis in electrical systems and power networks.

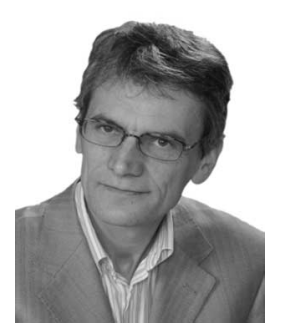

Piotr J. Chrzan (M'04) was born in Sopot, Poland, in 1954. He received the M.Sc., Ph.D., and Dr.Sc. degrees from Gdansk University of Technology, Gdansk, Poland, in 1978, 1988, and 1999, respectively.

Since 1980, he has been with the Faculty of Electrical and Control Engineering, Gdansk University of Technology, where he is currently a Professor and the Head of the Chair of Power Electronics and Electrical Machines. He has been an Invited Researcher several times in the Laboratoire d'Electrotechnique de Grenoble (LEG). He has held several Visiting Professor positions at the Institut National Polytechnique de Toulouse (LEEI-ENSEEIHT) and the University of Poitiers (LAII-ESIP). He is a member of the Editorial Committee of the Revue Internationale de Génie Electrique (Hermes-Lavoisier). His current research interests include aerospace electrical systems, modeling and control of electrical machines, power converters, and electromagnetic compatibility. 